\title{
Analytical Pluralism in Qualitative Research: A Meta-Study
}

Nicola J. Clarke, Martin E. H. Willis, Jemima S. Barnes, Nick Caddick, John Cromby, Hilary McDermott \& Gareth Wiltshire

This is a pre-publication draft of an article published in Qualitative Research in Psychology.

To cite this article:

Nicola J. Clarke, Martin E. H. Willis, Jemima S. Barnes, Nick Caddick, John Cromby, Hilary McDermott \& Gareth Wiltshire (2014): Analytical Pluralism in Qualitative Research: A MetaStudy, Qualitative Research in Psychology

To link to this article: http://dx.doi.org/10.1080/14780887.2014.948980 


\title{
ANALYTICAL PLURALISM IN QUALITATIVE RESEARCH: A META-STUDY
}

\begin{abstract}
Recent interest in analytical pluralism - the application of more than one qualitative analytical method to a single data set - has demonstrated its potential to produce multiple, complex and varied understandings of phenomena. However tensions remain regarding the commensurability of findings produced from diverse theoretical frameworks, the practical application of multiple methods of analysis and the capacity of pluralism to contribute to knowledge in psychology. This study addresses these issues, through a critical interpretation of existing qualitative studies that utilised analytical pluralism. Using a meta-study design, we examined the use of theory, application of methods and production of findings in studies that had adopted qualitative analytical pluralism. Following comprehensive database searches, 10 articles were included in the analysis. Epistemological and ontological considerations, the influence of decisions made in the practical application of pluralism and approaches to interpreting findings produced from multiple analyses are discussed, and implications for future research are considered.
\end{abstract}

In seeking to explore the diversity and complexity of our social world, psychologists are increasingly turning to pluralistic methods of research. Indeed, Qualitative Research in Psychology devoted a special issue to the theoretical and practical considerations of pluralism in qualitative research (Frost \& Nolas, 2011). There are many possible kinds of pluralism, including the use of multiple methods, data sources, theories, or researchers. However, the focus of this paper reflects a burgeoning interest in analytical pluralism; the combination of multiple methods of qualitative data analysis within the same study. For the purposes of this analysis, pluralism is defined as the application of more than one qualitative analytical method to a single data set. Put simply, analytical pluralism recognises that "a data set can tell us about a number of different things, depending on the questions we ask of it" (Willig, 
2013, p. 19). It offers researchers an alternative to the orthodox approach of adopting a specific, recognised mono-methodology; the uncritical adoption of which can lead to methodolatry (the reification and privileging of methods) and a reticence to adapt methods to suit the research context (Chamberlain, 2000; 2011; Chamberlain, Cain, Sheridan, \& Dupuis, 2011).

Advocates of analytical pluralism start from the position that different forms of knowledge produced through diverse methods of analysis may be viewed as complementary, rather than mutually exclusive, as each can reflect a different aspect of the phenomenon of interest (Frost et al., 2011). Analytic methods therefore provide tools which enable researchers to attend to different things in the data. By combining analyses which examine the data in a variety of ways (e.g. through emphasis of the individual or the social), analytical pluralism has the capacity to produce richer understandings of phenomena, and avoid reductionism (Kincheloe, 2001; 2005; Kincheloe \& Berry, 2004).

Additionally, some scholars maintain that multiple analytic approaches are appropriate for understanding a plural and complex world and that the variety of human expression cannot always be adequately represented by one framework alone (e.g. Chamberlain et al., 2011; Frost et al., 2011; Kincheloe, 2001; 2005). This stance suggests that the application of more than one analysis can enable researchers to explore the multiple dimensions of phenomena without being limited to a single perspective, and can allow for the maximum interpretative value to be gleaned from the data (Coyle, 2010). The potential benefits of this approach to psychological research are that; findings which may speak to different audiences can be produced; the strengths of one analytic method can be used to offset the limitations of another; and reflexivity may be enhanced through an increased focus on the impact of the researcher's biography, experience and application of technique (Frost et al., 2010).

Although the position and potential advantages of analytical pluralism have been articulated, there remain tensions and challenges which researchers wishing to adopt this approach must address. The practice of using multiple analyses within a single study can involve researchers attempting to mix disparate and sometimes dissonant approaches. Researchers may choose to pursue an integrated blend of findings, where the boundaries between different analytic frames are blurry - or to construct separate findings from each analysis, where the distinctions between methods are clear (Kincheloe, 2001). This demands that researchers are 
aware of, and maintain conceptual clarity between, the differences in the philosophical underpinnings of methodologies (Willig, 2013). This is of pertinence to research projects which utilise analytic methods imbued with elements from competing paradigms within the same study.

Concerns have been raised that methods of analysis should not be combined when the paradigms which underpin the methods are incompatible. Paradigms diverge on beliefs about the nature of existence (ontology), the possibility and character of valid knowledge (epistemology) and the nature of ethics and values (axiology). Thus, if paradigms are upheld as foundational and mutually exclusive, integrating opposing approaches may render findings incommensurable and incoherent (Lincoln, Lynham, \& Guba, 2011). This therefore requires researchers to recognise differences and find appropriate ways to engage with multiple ontological, epistemological and axiological positions to produce coherent theoretical understandings and explanations of phenomena. The task for researchers then, is to work creatively to "hold together interpretations that make sense within their own frames of reference but create epistemological tension when juxtaposed or integrated" (Coyle, 2010, p. 82). It is unclear whether researchers have to date adequately accounted for this issue.

Another consideration for pluralistic research is how to judge its quality. The diversity within qualitative research has led to competing claims as to what counts as quality, and different paradigms or approaches often have their own criteria for evaluating research (e.g. Cresswell, 2007; Seale, 1999). Pre-established criteria may present additional problems if researchers attempt to combine qualitative methods of analysis associated with diverse quality criteria. Suitable ways to enhance and judge the quality of analytical pluralism therefore requires further reflection from researchers.

Furthermore, the practical application of analytical pluralism to research in psychology may raise concerns which, due to the novelty of the approach, have not yet been fully addressed. Coyle (2010) questions how researchers discern which theoretical perspectives or methods are most suitable to apply to a data set, and how they decide the number of analyses to be performed within a study; given the aim of generating specific, meaningful implications, and the financial constraints of projects and word restrictions of journal articles. Once these decisions have been made, there are further considerations regarding how researchers undertake pluralistic analysis in practice. For example, whether data is read by the analyst 
from one perspective at a time while others are held in abeyance (using a technique similar to that of phenomenological bracketing; Ashworth, 1996) or whether the analyst moves flexibly within and between analyses (and if so, how rigour is maintained). Moreover, these decisions are both multiplied and complicated if a team of researchers performs multiple analyses.

There is also the danger that analytical pluralism could become a hollow rhetorical device if authors fail to convey a clear argument regarding its value within the specific research project (Chamberlain et al., 2011). Researchers may be tempted to adopt a pluralistic approach because it is perceived as cutting edge or innovative, without duly considering the requirements of their particular research aims or the implications of combining potentially disparate perspectives. Crucially then, researchers must demonstrate whether pluralistic findings can make a significant contribution to psychology. Whereas pluralism might enable insights into phenomena that would not otherwise be possible, it could merely reproduce the outcomes achievable using individual analyses separately - thereby becoming primarily an exercise in illustrating similarities and differences between analytical frameworks. The power of multiple analyses to extend or critique existing knowledge, improve practice, empower or emancipate is as yet undetermined.

In summary, analytical pluralism has been increasingly discussed and utilised in recent years. There are several reasons for adopting a pluralistic approach, including: an intention to produce diverse but complementary interpretations of phenomena; an aspiration to do justice to the variety of human expression and/or desire to avoid reductionism; and a wish to access as much as possible within the data. However, there are a number of unresolved tensions and unanswered questions - including issues surrounding commensurability, research quality, contribution to knowledge and the practical application of pluralistic methods - which this meta-study attempts to address. To examine these pertinent issues our research question asked; what can we learn from analytical pluralism in qualitative research?

\section{Method}

\section{Meta-Study}

Meta-study is a form of research involving the analysis of the theory, methods and findings of qualitative research and the synthesis of these insights into novel ways of thinking about 
phenomena (Paterson, Thorne, Canam, \& Jillings, 2001). As Paterson and her colleagues explain:

[M]eta-study represents a discrete and distinct approach to new inquiry based on a critical interpretation of existing qualitative research. It creates a mechanism by which the nature of interpretation is exposed and the meanings that extend well beyond those presented in the available body of knowledge can be generated. As such, it offers a critical, historical, and theoretical analytic approach to making sense of qualitatively derived knowledge (2001, p. 2).

Meta-study is the investigation of the results and processes of previous research. It is 'the research of research'. In this study we followed the approach described by Paterson et al. (2001). This involves not only the analysis of primary research results but incorporates reflection on the perspectives and processes involved in those studies. Of principal concern is the critical interpretation and synthesis of existing knowledge of the phenomenon of interest, and the identification of potential directions of future research. We selected a meta-study analysis as it is suitable for synthesising findings produced from diverse research approaches and therefore enabled us to compare and contrast the studies that applied pluralism in different ways, using various analytic methods. It also provided a structure which allowed us to deconstruct the studies we examined and explore the theoretical, methodological and analytic components of the papers to decipher what we could learn from them. This was beneficial given the importance of theory and method for pluralism and the implications of these in the tensions and questions we had identified.

Meta-study involves systematic analysis of three components: meta-theory, meta-method, and meta-data analysis (meta-findings). The purpose of these analyses is to reveal similarities and differences between studies and extrapolate new theoretical and practical implications. Meta-theory comprises the study of the theoretical and philosophical perspectives and assumptions underlying the research design. This involved a critical exploration of theoretical frameworks and underlying paradigmatic assumptions which guided each of the studies. We examined how theory was applied within the papers and how this shaped the research question, the choice of methods and construction of findings. Meta-method requires researchers to scrutinise the research design, methodologies and methods adopted within the studies. This meant considering the rigour and epistemological soundness of research and 
how methods influenced the findings produced. Meta-data analysis is the study of the findings of research. This involved a critical examination and reinterpretation of the analysis and findings presented by the studies. Pluralistic findings were compared across the papers to identify similarities and differences, and interpreted in terms of our research question. Finally, meta-study entails a final synthesis stage which brings together the analysis of theory, methods, and findings to offer new interpretations. For our study this consisted of combining reflections from across the three analyses to identify implications for future pluralistic research.

\section{Search Strategy}

A systematic literature search was undertaken by six members of the research team. Studies were primarily identified through searching relevant electronic databases: Web of Science, PsychInfo, PubMed, Science Direct, Scopus, and Google Scholar. The search terms used for each database were 'polyvocal', 'poly AND vocal', 'dual analysis' (dual analy*), 'multiple analysis' (multiple analy*), 'crystallisation', 'crystallization' and 'pluralism' (pluralis*), with additional searches using hyphenated variants where appropriate. Each search term was utilised twice; initially by itself, then paired with the term 'qualitative' to reduce the number of returns on some searches. Inclusion criteria were established and comprised: studies written in English; published in peer reviewed journals; undertaken within the social sciences (including psychology); wholly qualitative in nature; and where one data set had been analysed using more than one qualitative method. The searches were not limited by publication dates. In total, 28 relevant articles were identified as a result of the initial searches. In consideration of the relatively uncommon use of qualitative analytical pluralism (Frost \& Nolas, 2013), the articles were deemed sufficient in number and diversity to allow for comparisons to be drawn and for the research question to be answered fully (Paterson et al., 2001).

All 28 articles were systematically checked in detail by at least two researchers against the inclusion criteria. Eight duplicates were subsequently identified and discounted. Citation searches were undertaken on all identified articles and reference lists checked for any further studies which met the inclusion criteria. In addition, two key authors from the identified literature were contacted by e-mail and asked to comment on the comprehensiveness of the search results and to suggest further articles not identified as a result of the searches. No 
additional papers were suggested. The search strategies therefore resulted in a total of 20 relevant articles.

\section{Data Abstraction and Analysis}

Data abstraction was directed through the use of a template which facilitated a detailed examination of each article. This allowed salient aspects of the articles to be summarised for further analysis. The template - developed in accordance with the three meta-study components - guided analysis through the following questions:

- What analyses are employed?

- Are ontologies and/or epistemologies specified?

- How does theory inform the paper?

- How adequately does the paper describe the methods used?

- Are the analyses/findings adequately supported by data?

- What discussion is there of the capacity of different methods of analysis to produce different findings?

- Are the relations/connections between the findings of the different methods of analysis adequately discussed?

- What limitations does the paper acknowledge?

- What strengths/weaknesses does the paper have?

- What are the key findings from this paper in terms of analytical pluralism in qualitative research?

Each article was reviewed independently by at least two researchers and through subsequent discussions a joint summary of the analysis was produced for each paper. These summaries were then used to inform our meta-theory, meta-methods, and meta-findings. As a result of this detailed evaluation of the articles and much discussion in group meetings about what constituted evidence of analytical pluralism, a further 10 papers were excluded from this meta-study. For example articles which described the application of a pluralistic approach but did not present an analysis of data were rejected. Notes were kept of each meeting to record our decisions. The selection procedure is summarised in Figure 1.

In conducting the analysis, three members of the research team worked together on producing a meta-theory, two on producing meta-methods, and two on meta-findings, using 
the article summaries and referring back to the original papers. Regular meetings were held to reflect upon and engage with any presuppositions that may have formed in the process of deciding to undertake a meta-study of qualitative methodological pluralism. Sharing our initial findings with the group strengthened the analysis process as members could offer additional and sometimes alternative interpretations and implications for practice. Although we aimed to minimise the impact of our personal biases on the meta-study, we acknowledge that our analysis and implications are derived from our interpretations of the authors' presentations of pluralistic data. Next, the written analyses were circulated to the entire group for feedback and additional suggestions. Finally we regrouped for further discussion of our observations, conclusions and implications for practice, before collaboratively writing this paper.

\section{Figure 1. Article Selection Procedure}

Web of Science, PsychInfo, PubMed, Science Direct, Scopus and Google Scholar databases searches completed

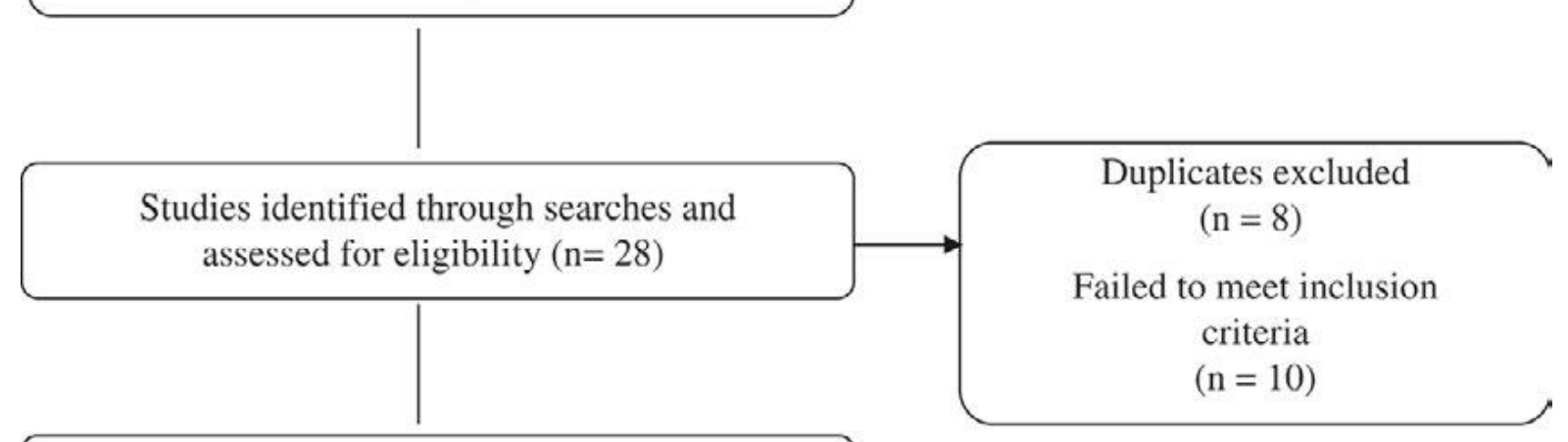

Studies meeting inclusion criteria $(\mathrm{n}=10)$

\section{Findings and Discussion}

\section{Meta-theory}

This section of the study was guided by the questions: how was theory used within the articles; and how were ontological and epistemological concerns addressed? The pluralistic approach was frequently advocated on the basis that complex and varied understandings of phenomena were produced through the application of different analysis methods to data. Analytical pluralism was used by authors to extract as much meaning as possible from the 
data (Frost, 2009), and to construct holistic, multi-layered understandings, which were deeper than those which one method of analysis could offer alone (Simons, Lathlean, \& Squire, 2008) and greater than the sum of their parts (Wickens, 2011). For example, authors combined approaches such as thematic and narrative analysis to examine both the content and form of participants' accounts (Savage, 2000; Simons et al., 2008). Other studies employed multiple techniques from discursive psychology to explore the function of participants' talk (Honan, Knobel, Baker, \& Davies, 2000; Lyons \& Cromby, 2010).

It was the adoption of different theoretical frameworks, however - not simply different methods of analysis - that produced the most divergent findings within a study. For example, Frost et al.'s (2011) use of phenomenological and discursive analyses, which put different emphasis on agency or structure respectively, illuminated the embodied, gendered and constructed nature of second-time motherhood. Honan et al. $(2000$, p. 9) illustrated the "constitutive force of theory" by comparing separate interpretations of a corpus of qualitative data using discourse theory, feminist poststructuralism, and ethnomethodology. Although these three approaches shared an interest in language, Honan and colleagues acknowledged that each perspective enabled different 'work' to be done with the data, and demonstrated how they produced contrasting versions of their participant's world; as constituted by discourses, subject positions or interaction. Conversely, Lyons and Cromby (2010) provided an interesting commentary on the extent to which the multiple discursive frames used to explore an extract of a transcript where heightened blood pressure was recorded, reflected different aspects of the embodied nature of social interaction, as the analyses arguably identified varying conceptualisations of the same discursive work. This suggests that research can highlight the multi-dimensional nature of phenomena when theories with divergent assumptions about the social world are employed, and provides our first implication for researchers applying analytical pluralism.

Within the sample of papers there was limited discussion of the relationship between paradigmatic assumptions and analytic methods, meaning in some cases it was unclear how paradigmatic tensions had been addressed. Without engaging with the inherent tensions arising from the inclusion of different perspectives with potentially opposing epistemological and ontological assumptions in the same study, pluralistic research can be left open to the challenge of incommensurability. That is, if the philosophical assumptions from contradictory 
paradigms are mixed indiscriminately, the coherent simultaneous practice of them becomes impossible (Lincoln et al., 2011).

Despite this, few of the articles in this study directly addressed the matter of commensurability. Some researchers avoided incoherence by employing analytical techniques underpinned by the same ontological position, for example critical realism (Robinson \& Smith, 2010) or expressivist-constructivist theory of language (Simons et al., 2008). These papers subscribed to an epistemological pluralism, where multiple methods of analysis are used to produce different knowledge or perspectives of an object (epistemic project) without implying a statement about the nature of the object (ontological status). This is closely related to what (Bhaskar, 1989, p. 13) referred to as the epistemic fallacy - "that ontological questions can always be reparsed in epistemological form: that is, that statements about being can always be analysed in terms of statements about our knowledge (of being)". For example, if a narrative analysis is performed for the purpose of gaining knowledge about how stories help people to understand the social world (epistemological) and not for the purpose of imposing the notion that humans are essentially story-telling beings (ontological), other, alternative analyses can also be accommodated. Alternatively, ontological pluralism (although not a position that any of the articles we examined explicitly aligned to) foregrounds the assumption that the nature of existence itself is multiple and plural. This stance rejects the notion that different philosophical positions are fundamentally incompatible and encourages multiple paradigms to be held together dialectically, in order to appreciate various understandings of the phenomena being studied. Endorsing an ontological pluralist perspective, strategies for working with multiple paradigms within a single study have been proposed, including pragmatism (e.g. Biesta, 2010), crystallisation (e.g. Ellingson, 2009) and dialectical pluralism (e.g. Johnson \& Stefurak, 2014). This may appeal to researchers who feel restricted working within a single paradigm. However, we caution that this position may tacitly encourage the privileging of multiple methods over mono-method studies, and introduce the view that pluralism can be used to access a more accurate representation of reality. Authors of the articles in this study avoided claiming that analytical pluralism was a means of getting closer to a true reality, instead describing that although findings may overlap they represent different emphases of meaning (e.g. Savage, 2000). 
In light of the theoretical considerations discussed here, we outline two methodological techniques which (in our view) may enable pluralistic researchers who wish to embrace epistemological pluralism to reconcile theoretical tensions. Firstly, bricolage may be a useful tool, as Wickens (2011) illustrated in her investigation of power in written texts. Bricolage involves attempts to "find and develop numerous strategies for getting beyond [the] one dimensionality of single method research" (Kincheloe \& Berry, 2004, p. 23) and is perhaps more usually associated with the decomposition of methods than their pluralistic mixing. Wickens (2011) utilised this technique from within an overarching critical, poststructuralist stance (avoiding incoherence) to move dynamically and fluidly between analytic methods, examining the recurring patterns, specific linguistic features and narrative description within the texts, and their interpretive connections. For Wickens, the bricolage approach allowed data to become prism-like, meaning it could be viewed from various angles which each offered a different representation of the data. Here, each prism angle can be considered as producing different forms of knowledge (an epistemological rather than an ontological claim). This was similar to the practice used by Simons et al. (2008, p. 129) of shifting focus to analyse interview data from community mental health nurses. This involved "viewing the same object from the same [theoretical] standpoint but adjusting the lens to bring into view particular aspects of the phenomenon", and highlights another potential technique for researchers aiming to construct multiple ways of knowing. In summary, this distinction between epistemological and ontological pluralism may help ease the concerns of some researchers who may view the issue of commensurability as a barrier to pluralism.

Other articles in our study did give consideration to ontological and epistemological concerns, but adequate resolutions were not always reached. When research was located within a particular paradigm, it was sometimes unclear as to whether this was an ontological or epistemological position, or both, meaning it was difficult to determine the nature of the knowledge produced in these studies (e.g. Burck, 2005; Lyons \& Cromby, 2010).

Frost et al.'s (2011) pluralism mixed constructionist, interpretative, and realist paradigms, arguing that the diversity of human expression cannot be adequately captured by a single framework. To demonstrate the commensurability of approaches, Frost et al. (2011) described the similarities between analyses (e.g. a common focus on language, meaningmaking or the identification of themes) and outlined how the findings produced enriched 
understanding by reflecting different aspects of the same phenomenon. This assumes that if analytic techniques can be made commensurable then paradigms can too, which may not necessarily be the case. A more explicit distinction between analyses and paradigms would have perhaps been useful here. Nonetheless, the authors acknowledged that their research lacked an "interpretative integration of the data" (p. 110), which would have required tensions between the somewhat incommensurate paradigms to be resolved. A fully integrated interpretation of findings was, however, acknowledged by King et al. (2008) as unachievable. Although there was a high degree of similarity between the various phenomenological interpretations of the experience of mistrust, the authors were unable to resolve disagreements arising from conflicting epistemological positions of the researchers. In contrast, Savage (2000) did not seek to amalgamate findings produced from different theoretical stances to avoid the implication that a more accurate representation of the world would result. Instead, Savage proposed that rather than seeing traditions such as realism and post-modernism as opposing, they might be more usefully understood as dialectical or mutually informing, allowing for the "construction of different, and even contrary, versions of the social world" (p. 1495).

Our second suggestion for pluralistic researchers is, therefore, to be reflexive toward how various epistemological and ontological positions are to be distinguished between, juxtaposed or creatively combined, in order to explain how knowledge was produced and maintain what Walsh and Koelsch (2012) refer to as structural integrity. Walsh and Koelsch recommend that when combining different approaches, qualitative researchers should explicitly consider how epistemological, methodological, and procedural components adhere. Pluralistic analysis requires "explicating a coherent rationale that considers the question, context, and assumptions that presumably hold the study together" (Walsh \& Koelsch, 2012, p. 386).

\section{Meta-methods}

In this section we consider how qualitative pluralistic analysis has been performed in practice by exploring: the types of data analysed; the methods of analysis used; the rationales for the choice of methods; the number of analyses conducted; and the ways in which pluralistic analyses were applied. 
In the studies reviewed, analyses were applied to data from interview texts, ethnographic observations and fictional novels - an encouraging sign that analytical pluralism can be used with a variety of data. Frost et al. (2011) justified selecting an interview transcript for pluralistic analysis on the grounds that the data were "rich in coherent and evolving stories, metaphors, and other linguistic features and included thoughtful self-analysis" (p. 96). Similarly, Simons et al. (2008) explained that the storied nature of the data lent itself to narrative analysis. Although this makes practical sense, we question whether this rationale may marginalise or silence storytellers who are less eloquent or self-reflective; especially when narrative methods are used. The choice of transcription system may also preclude some forms of analysis. For example, conversation analysis (Sacks, Schegloff, \& Jefferson, 1974) is best applied when suitable transcription is used. With this in mind, we suggest that researchers might consider the extent to which data is accessible to different analytic techniques at the onset of the research process, so that appropriate data can be collected.

Table 1 details the variety of analysis methods employed in the studies we reviewed, illustrating how pluralism was performed using theoretically diverse methods (e.g. grounded theory with discourse analysis; Burck, 2005) or variants of the same analytic approach (e.g. phenomenological methods; King et al., 2008). Earlier we observed that the adoption of different theoretical frameworks produced the most divergent findings. In contrast, Frost (2009) provided an example of how, instead, multiple analyses can be used within the same paradigm to do different things and achieve a more nuanced interpretation of data. Frost (2009) undertook two forms of narrative analysis; the first to identify the temporal structure and features of narratives within the interview; the second to examine meaning within the story and how the narrative was spoken, through a closer analysis of the prosodic and paralinguistic aspects of speech. Presented alongside an analysis of metaphor within the narrative and reflections on the role of the researcher in co-constructing the interview, Frost (2009) offered a detailed insight into the identity work, emotional experience and cultural discourses associated with being a mother. Frost's approach can be contrasted with Robinson and Smith (2010) who used interpretative phenomenological analysis with an interactive model analysis in a composite fashion. As the methods were used principally to organise and synthesise the interview data, there was little variation between the findings produced by the different techniques. 
Table 1. Summary of articles in meta-study

\begin{tabular}{|c|c|c|c|c|}
\hline Article & $\begin{array}{l}\text { Specified Ontology/ } \\
\text { Epistemology }\end{array}$ & Study Topic & Nature of the Data & Methods of Analysis Used \\
\hline Burck (2005) & $\begin{array}{l}\text { Social constructionist } \\
\text { paradigm (not specific about } \\
\text { ontology or epistemology) }\end{array}$ & $\begin{array}{l}\text { Experiences of } \\
\text { living life in more } \\
\text { than one language }\end{array}$ & $\begin{array}{l}\text { Semi-structured } \\
\text { interview }\end{array}$ & $\begin{array}{l}\text { Discourse Analysis, Grounded } \\
\text { Theory, Narrative Analysis }\end{array}$ \\
\hline Frost (2009) & None specified & $\begin{array}{l}\text { Experiences of } \\
\text { second time } \\
\text { motherhood }\end{array}$ & $\begin{array}{l}\text { Semi-structured } \\
\text { interviews }\end{array}$ & 4 Types of Narrative Analysis \\
\hline Frost et al. (2011) & $\begin{array}{l}\text { Realist, interpretative, \& } \\
\text { constructionist paradigms } \\
\text { (not specific about ontology } \\
\text { or epistemology) }\end{array}$ & $\begin{array}{l}\text { Experiences of } \\
\text { second time } \\
\text { motherhood }\end{array}$ & $\begin{array}{l}\text { Semi-structured } \\
\text { interview }\end{array}$ & $\begin{array}{l}\text { Foucauldian Discourse } \\
\text { Analysis, Grounded Theory, } \\
\text { Interpretative } \\
\text { Phenomenological Analysis, } \\
\text { Narrative Analysis }\end{array}$ \\
\hline $\begin{array}{l}\text { Honan et al. } \\
(2000)\end{array}$ & None specified & Studenthood & $\begin{array}{l}\text { Ethnographic case } \\
\text { study }\end{array}$ & $\begin{array}{l}\text { D/discourse Theory, } \\
\text { Ethnomethodology with } \\
\text { Conversation Analysis, Post- } \\
\text { structuralist Feminism }\end{array}$ \\
\hline King et al. (2008) & $\begin{array}{l}\text { Realist, critical realist, \& } \\
\text { relativist epistemologies; no } \\
\text { specified ontology }\end{array}$ & Mistrust & Depth interview & $\begin{array}{l}5 \text { Types of Phenomenological } \\
\text { Analysis }\end{array}$ \\
\hline $\begin{array}{l}\text { Lyons \& Cromby } \\
\text { (2010) }\end{array}$ & $\begin{array}{l}\text { Process approach (not } \\
\text { specific about ontology or } \\
\text { epistemology) }\end{array}$ & $\begin{array}{l}\text { Relations between } \\
\text { social interaction } \\
\text { and physiology }\end{array}$ & $\begin{array}{l}\text { Recorded } \\
\text { conversation in } \\
\text { conjunction with } \\
\text { blood pressure data }\end{array}$ & $\begin{array}{l}\text { Loughborough Discourse } \\
\text { Analysis, Positioning Theory, } \\
\text { Gaining Voice, Joint Action }\end{array}$ \\
\hline $\begin{array}{l}\text { Robinson \& } \\
\text { Smith (2010) }\end{array}$ & $\begin{array}{l}\text { Critical realist epistemology; } \\
\text { no specified ontology }\end{array}$ & $\begin{array}{l}\text { Crisis episodes in } \\
\text { early adulthood }\end{array}$ & $\begin{array}{l}\text { Semi-structured } \\
\text { interviews }\end{array}$ & $\begin{array}{l}\text { Interpretative } \\
\text { Phenomenological Analysis, } \\
\text { Interactive Model }\end{array}$ \\
\hline Savage (2000) & $\begin{array}{l}\text { Realist and constructionist } \\
\text { approaches (not specific } \\
\text { about ontology or } \\
\text { epistemology) }\end{array}$ & $\begin{array}{l}\text { Nursing culture in } \\
\text { relation to staff } \\
\text { retention and } \\
\text { patient care }\end{array}$ & Interview & $\begin{array}{l}\text { Narrative Analysis, Thematic } \\
\text { Analysis }\end{array}$ \\
\hline $\begin{array}{l}\text { Simons, Lathlean } \\
\& \text { Squire (2008) }\end{array}$ & $\begin{array}{l}\text { Constructionist and } \\
\text { expressivist-constructivist } \\
\text { epistemologies; no specified } \\
\text { ontology }\end{array}$ & $\begin{array}{l}\text { Nurses' experience } \\
\text { of delivering a } \\
\text { mental health } \\
\text { intervention }\end{array}$ & Active interviews & $\begin{array}{l}\text { Narrative Analysis, Thematic } \\
\text { Content Analysis }\end{array}$ \\
\hline Wickens (2011) & $\begin{array}{l}\text { Critical realist, } \\
\text { constructionist/ivist, } \\
\text { interpretivist approaches } \\
\text { (not specific about ontology } \\
\text { or epistemology) }\end{array}$ & $\begin{array}{l}\text { Power in LGBTQ } \\
\text { fiction }\end{array}$ & LGBTQ Novels & $\begin{array}{l}\text { Discourse Analysis, Literary } \\
\text { Analysis, Thematic Analysis }\end{array}$ \\
\hline
\end{tabular}

Perhaps unsurprisingly, authors provided different rationales for their selection of analytic methods. However, their decisions highlight some noteworthy implications for future research. Most commonly, researchers justified their choice because of the suitability of methods to the research question. For example, Burck's (2005) rationale was rooted in the pragmatic concerns and interests of systemic psychotherapy research. Burck described at 
length the suitability of approaches for exploring data from family therapy and emphasised how analyses can be used to explore different research questions. In comparison (and as noted above) Simons et al. (2008) described how the storied nature of data prompted the deployment of a narrative analysis. This implies that some preliminary reading of the data must have occurred, and as the influence of the researcher in this initial analysis was inevitable, we suggest that a data-driven rationale for selecting analytic techniques may be problematic.

Epistemological fit and similarity between analytical frameworks was also cited as a reason for selecting methods of analysis in pluralistic research. Savage (2000) justified choosing a thematic analysis as it was consistent with a realist perspective and shared a common focus on process and meaning with narrative analysis. Similarly, Robinson and Smith (2010) explicitly presented a comparison of the interpretative phenomenological and interactive model analyses used to highlight the features common to both methods, reflecting the authors' commitment to commensurability.

Lastly, the authors of the methodological papers included in this meta-study - which aimed to explicate the capacity of qualitative pluralistic analyses to produce different findings selected methods that suited the experience of the researchers, primarily for illustrative purposes (Frost et al., 2011; Honan et al., 2000; King et al., 2008). Although this may present a practical solution to the challenge of conducting pluralistic analysis in a research community which tends to be theoretically and methodologically specialised, we would encourage researchers to reflect upon the extent to which their methodological expertise both enables and constrains the research questions that can be addressed. For example, King et al. (2008) provided a useful description of the authors' individual approaches to phenomenological analysis at the end of their paper, enabling the reader to understand how the underlying assumptions and biases of the researchers influenced the analysis.

Pluralistic researchers must also decide how many analyses should be performed on a single data set. The articles we studied utilised up to four1 different techniques, as illustrated in Table 1. Certainly, the potential of pluralism to construct multiple, complex findings may lead researchers to conclude that more analyses are better. Although the practical constraints of this are clear, we would also encourage researchers to reflect upon whether there can be too many ways to helpfully examine a phenomenon. The assumption that more analyses are 
better comes with a risk of producing complicated findings without saying anything of real consequence; that is, with no significant implications for either theory or practice. Thoughtful construction of pluralistic research questions may help researchers to negotiate this balance. Overall, rationales for choosing which analytic methods to include (and how many) in pluralistic studies were both theoretical and practical. The foremost consideration for future pluralist researchers is perhaps then, that analyses offer a coherent fit with the research question and philosophical assumptions of the study.

Across the articles in this meta-study, the explanation of how methods of analysis were applied varied. In some studies, methodological procedures were described in detail (e.g. Savage, 2000; Simons et al., 2008), whereas in others the analysis process was less transparent. In light of the growing interest of pluralistic analysis in psychology (Frost \& Nolas, 2011), we recommend that sufficient detail of methodological procedures are reported, to enable readers to understand how to undertake multiple analyses and how knowledge was produced. For pluralistic research to demonstrate rigour - a widely accepted criterion for judging the quality of qualitative research (e.g. Tracy, 2010; Yardley, 2000) - providing adequate description of the procedures used to select, transform and organise data in the research paper is advisable. Specifically, we were concerned that in the two studies that used grounded theory analysis, it was not made clear whether a full or abbreviated version of the method was applied (Willig, 2013). Indeed, we would question whether a full grounded theory (i.e. using the techniques of theoretical sampling and theoretical saturation) is achievable with analysis of a single interview transcript.

In practice, pluralistic analysis was performed by researchers in a variety of ways. In four studies a single researcher analysed a data set in multiple ways (Burck, 2005; Frost, 2009; Savage, 2000; Wickens, 2011), whereas three papers used at least two researchers to undertake multiple analyses together (Lyons \& Cromby, 2010; Robinson \& Smith, 2010; Simons et al., 2008). Others used a team of researchers to independently analyse a data set each in a different way (Honan et al., 2000), or independently followed by a group crossanalysis (Frost et al., 2011; King et al., 2008).

Each approach arguably entailed a different set of advantages and challenges. Using a team of researchers to independently analyse a data set meant that others with expertise in different analytic techniques were able to contribute to projects. However, King et al. (2008) 
discussed the difficulties involved in the group process of producing a consensual analysis, reflecting that unresolved tensions were derived from researchers' different epistemological positions. Reflecting on their involvement in the analysis process, Frost et al. $(2010 ; 2011)$ felt that focusing on an interview text alone allowed for a fresh perspective. Conversely, others described feeling removed from the interview process, noting how they would have conducted the interview in a manner more aligned to their analytical approach. Using different researchers may enhance the diversity of interpretations, as each researcher brings their own subjective stance to the data. However without a group cross-analysis process, findings may remain separate and disconnected rather than offering fluid, dynamic understandings of the research topic.

For the individual researcher undertaking pluralistic analysis, the ordering of analytical approaches must be considered. Analyses were performed sequentially or simultaneously by researchers, but little attention was given to the interaction between methods. It may be possible (for example) that the first analysis could obscure alternative meanings that might have been available had another analysis been undertaken initially.

In articles where analytic techniques were explicitly applied in sequence, some authors acknowledged the influence of the initial analysis in shaping their later interpretations. Frost (2009) used the transcript and her experience of the interview to be guided sequentially from one analytical perspective to another, and described how this approach allowed for a shift in perspective when she recognised a point of interest in the data. Lyons and Cromby (2010) used elevated blood pressure readings to direct them to a particular section of interview text, but discussed whether in the absence of physiological data, they would have still arrived at the same section of the transcript. Using multiple analyses simultaneously, Wickens (2011) described using a triple-entry journal to record excerpts of data, analytic ideas and personal responses to texts. This allowed her to move fluidly from one analytic method to another and attend to the connections between both critical and reflexive interpretations of the texts. We suggest, therefore, that pluralistic researchers working independently reflect upon how analytic methods are sequenced or how simultaneous analysis should be approached.

A challenge facing all pluralistic researchers is how the personal subjectivity and biography of the analyst(s) influences the research process. Chamberlain et al. (2011) suggested that "adopting multiple methods and using them creatively and critically demands and promotes 
reflexive engagement with every aspect of the research practice" (p. 166). If pluralism requires researchers to shift between theoretical perspectives in order to represent the multidimensional nature of phenomena, it may be necessary for researchers to reflect upon their own proclivities. Reflexivity was addressed in five papers (and in a companion paper to Frost et al., 2011; Frost et al., 2010). Exploring the researcher's role in constructing interview dialogue was one way in which authors demonstrated reflexivity. King et al. (2008) attended to the researcher's embodied experience of empathy during the interview, and Burck (2005) and Frost (2009) provided examples of how the interviewer had influenced the direction of the discussion by closing down or opening up certain topics. Frost (2009), in fact, explicitly used this reflexive analysis as a method of producing an additional layer of understanding.

Working with multiple data sources, Wickens (2010) used journal entries to reflect on how interpretations were formed and Honan et al. (2000) highlighted how different theoretical approaches oriented analysts toward certain types of data to build their case, and questioned the extent to which the findings reflected their participant or the analyst and their chosen perspective. Frost et al. (2010) also compared the impact of individual researchers on the production of findings, noting that the analyst's level of experience and epistemological stance influenced their use of language. Some analysts distanced themselves from their role in the interpretative process by selecting to write in the third person, and those with relatively less experience tended to use a "more authoritative voice" in their accounts than the "tentative" language used by others (Frost et al., 2010, p. 457). The examples of reflexivity provided in these studies illustrate how analytical pluralism invites and encourages researchers to reflect upon their role in constructing data and subsequent (multiple) interpretations and, as Frost et al. (2010) proposed, may provide a starting point for enhancing transparency and trustworthiness in research.

\section{Meta-findings}

For the final part of the meta-study we examined the findings produced by qualitative pluralistic analysis, by considering the findings that were presented, the ways authors interpreted them, and their utility and value for psychology.

By adopting a pluralistic approach the papers in this meta-study produced multiple, diverse understandings of the research topics under investigation. However, how authors presented their findings varied, demonstrating the flexible nature of analytical pluralism. Eight of the 
articles we reviewed presented separate findings for each analytic technique used, which enabled comparisons to be drawn between the interpretations (albeit in different ways, discussed below). Robinson and Smith (2010) produced fully integrated findings from a combined analysis, and uniquely King et al. (2008) presented findings from a combined analysis as well as separate interpretations from each analyst.

How authors selected their data inevitably influenced the findings that were produced. Multiple interpretations of the same piece of data were presented by Frost et al. (2011), Lyons and Cromby (2010) and Savage (2000), allowing the reader to directly compare the interpretations derived from each perspective. Alternatively, other authors selected different extracts of data to illustrate findings, choosing either different sections of the same interview transcript (King et al., 2008), or selecting data from across a variety of sources (Burck, 2005; Honan et al., 2000; Simons et al., 2008; Wickens, 2011). Honan et al. explained that using different data to represent findings from separate analyses was necessary, as each approach "works with its own vocabulary... and calls on different orders of evidence for its claims to adequacy" (2000, p. 30); thus highlighting how pluralism can enhance transparency in the research process.

The selection of data and presentation of findings determined the comparisons that could be made between the multiple and potentially divergent interpretations; providing a further implication for pluralistic researchers. Authors compared and contrasted the findings produced by pluralistic analysis in several ways, ranging from a standalone discussion of each analysis to a fully integrated presentation of several interpretations. Burck (2005) and Savage (2000) offered little or no comparisons between findings, with interpretations standing side by side, but discussed separately. Exploring how pluralistic analysis could be used to build up layers of meaning, Frost (2009), Lyons and Cromby (2010) and Simons et al. (2008) conducted analyses in a sequential manner. An initial analysis was performed to identify meaning in the data, which then guided the subsequent analyses. In this way, findings were connected by a common feature or meaning in the data.

In contrast to constructing meaning sequentially, some authors worked across findings, comparing explicitly the different interpretations from each analysis. Different findings were shown on occasion to contradict others (Honan et al. 2000), produce similar interpretations (for example when the same text was drawn upon to illustrate related themes; Frost et al., 
2011), or even highlight both converging and diverging interpretations of the phenomenon under study (King et al., 2008). In these three papers, the capacity of pluralistic analysis to produce multiple possibilities for understanding was demonstrated through the comparisons between interpretations, as each finding was considered to reflect a different aspect of the same phenomenon (Frost et al., 2011). For example, Honan et al. (2000) concluded their article by pulling together the various versions of their participant that were made available by the different perspectives, commenting that "our interest definitely is not in which is right or better but rather in when each one could be useful and for what purpose" (p. 30). This suggests that findings from pluralistic analysis have the potential to be accessible to a diverse audience, as the most relevant interpretation to the reader can be extracted (Frost \& Nolas, 2013).

Furthermore, presenting different readings of qualitative data together allowed for multiple possibilities of being to be constructed, rather than limiting participants to an 'either/or' ontological status. Frost et al. (2011) presented their participant as a phenomenological, realist and postmodern agent, recognising that this may change fluidly depending on her context and situation. Similarly, Honan et al. (2000) described assigning different powers and discursive resources to their participant, by constructing contrasting versions of her social world. It therefore appears that when multiple interpretations are treated with equal significance, analytical pluralism offers researchers the potential to honour the complexity of participants' lives and avoid what Bakhtin (1984 [1963]) referred to as 'finalising' what any individual or group is, or could become.

The final approach was to pursue an integrated synthesis of findings, where it was less clear as to how each form of analysis contributed to the findings produced (King et al., 2008; Robinson \& Smith, 2010; Wickens, 2011). Wickens (2011) argued that the overall emphasis of her bricolage approach was on creating "a combined picture [that] provides such a rich and evocative depicture that is more than the sum of its parts" (p. 161). Presenting a combined interpretation meant that any inconsistencies or contradictions between findings were overlooked, with the exception of

King et al. (2008) who discussed the separate interpretations produced by individual analysts alongside the integrated synthesis. This approach provided a detailed, idiographic account of the embodied, relational experience of mistrust and enabled the reader to see how the 
individual phenomenological interpretations varied, depending on the extent to which the analyst considered the participant's words to reflect their reality.

In view of the capacity of analytical pluralism to construct complex, multi-layered understandings of the phenomena we study in psychology, an advantage of this approach may be that research questions can be tackled from multiple perspectives. By embracing the diversity (and limitations) of what different analyses can do, researchers were able to address different research questions related to the same topic concurrently (e.g. Burck, 2005). A fundamental aim of research is to produce findings which contribute to knowledge. However, as many of the papers included in this meta-study declared methodological aims, it was difficult to judge whether studies using pluralism made a significant contribution to knowledge in their respective areas of research. Six articles did not relate the findings produced back to existing knowledge of the topic under investigation. Of the remaining papers, Frost (2009) generated future avenues for research and Simons et al. (2008) provided implications for nursing practice. Robinson and Smith (2010) proposed a model for understanding the process of early adult psychological crisis, and Lyons and Cromby (2010) discussed how discursive analysis may be combined with blood pressure data in order to develop a more embodied analysis in social psychology. These examples highlight how analytical pluralism can suggest future directions for research, produce implications for practice, build theory and develop methodological techniques.

However, we suggest that it is the comparison drawn between different interpretations that can offer something more to research in psychology than perhaps traditional monomethodological studies can. Whether meaning is built up sequentially from an initial theme, or derived from comparisons across findings, this form of interpretation encourages researchers to engage with the creative tensions that arise when different perspectives on the same phenomenon are brought together within a particular study and emphasises "learning from difference" (Kincheloe, 2001, p. 686). Moreover, the contrasting of perspectives can avoid a type of pluralistic methodolatry - the privileging of multiple methods in the belief that two or more are better than one - by focusing on how different interpretations may both converge and diverge in their understanding of the research topic of study. Ultimately, analytical pluralism should be more than simply a parade of the various 
methods available to us; it should be used creatively and productively to advance knowledge in psychology.

\section{Conclusions and Implications for Future Research}

Through this meta-study of qualitative analytical pluralism, we have closely examined the use of theory, application of methods and construction of findings in studies which have utilised more than one method of qualitative data analysis to explore meaning within a single data set. Analytical pluralism enables researchers to produce rich, varied understandings of phenomena, and opens up multiple possibilities for interpretation because it avoids privileging any particular approach or framework over another. This form of pluralism can offer alternative and interesting ways of approaching psychological research questions.

Alongside these advantages, the application of multiple data analysis methods presents challenges for researchers to negotiate. From our analysis of the papers in this study, we suggest that analytical pluralism can be used to highlight the multi-dimensional nature of phenomena when perspectives with divergent assumptions about the social world are employed. This requires researchers to clarify and distinguish between their epistemological and ontological positions and illustrate how their research maintains "structural integrity" (Walsh \& Koelsch, 2012). That is, researchers need to find ways to demonstrate coherent links between theory, method and findings and explain how findings produced from multiple analyses can remain commensurate or complementary. Our distinction between epistemological pluralism and ontological pluralism may be useful here, together with techniques such as bricolage (Kincheloe, 2001; 2005) or shifting focus (Simons et al., 2008), which allow for different ways of knowing to be constructed within a consistent ontological perspective. Alternatively, approaches like dialectical pluralism (e.g. Johnson \& Stefurak, 2014) offer ways of interacting with paradigmatic tensions.

Although the articles in this meta-study did not explicitly discuss the issue of quality in pluralism, there were examples of ways in which authors sought to ensure rigour in research. By engaging in reflexivity, researchers described an awareness and critique of their role in constructing data and multiple interpretations, suggesting that a pluralist approach may be used to enhance transparency and trustworthiness in research (Frost, 2011; Frost et al., 2010). Working with multiple analytic frames enabled authors to be sensitive to polyvocality and to represent the variety and multiplicity of perspectives within their data. This avoided 
finalizing participants' accounts, an ethical concern for researchers. Comparing the papers in this study also reinforced the importance of reporting qualitative methodological procedures in sufficient detail. Although this is not an issue unique to pluralistic studies, we advise that researchers using this approach provide adequate description of the techniques used to select, transform and organise data in their research, in order to demonstrate rigour. Considering the variation in how pluralistic analysis was performed in the papers we reviewed, we err towards suggesting that studies are judged on their individual merits and limitations. Therefore, scholars may wish to consider adapting their criteria for what constitutes good research when evaluating individual pluralistic studies, as universal indicators may not be appropriate (see Smith \& Deemer, 2000 for a discussion of the problematic nature of fixed criteria). Tracy (2010), for example, proposed eight common end goals of strong research (including rigour, credibility and meaningful coherence) rather than universal criteria for the practice of qualitative research, which may be more suitable for judging the quality of pluralistic research.

The purpose of this meta-study was to address the question: what can we learn from analytical pluralism in qualitative research? On the basis of our analysis, we conclude that pluralism has the potential to contribute to knowledge production; in particular through an exploration of the tensions that arise from combining different perspectives within the same study. Potentially, it is the comparisons drawn between interpretations that can offer something more to research in psychology, not least through promoting a reflexive critique of "the social and intellectual unconscious embedded in the analytic tools and operations used" (Johnson, Long \& White, 2000, p. 248). Indeed, for pluralistic research, the differences between findings may be more relevant than the similarities. There is however, a caveat to this. Although not a position adopted by any of the authors of the papers in this meta-study, we caution against a view that places multiple methods of analysis in a hierarchy above traditional mono-method studies. Certainly, the articles we reviewed have begun to illustrate the capacity of pluralism to produce interesting, polyvocal, sometimes diverging meanings from the same data set, but this does not mean that monomethodological work is not also valuable. As Kincheloe (2001) warns, pluralist researchers must resist complicity in knowledge production designed to regulate and discipline, as must those advocating monomethodological approaches. Instead, we advise that when research questions are carefully 
constructed, rationales for a pluralist approach and selection of methods are presented, and implications of decisions made in the practical application of pluralism are considered, that analytical pluralism offers a welcome addition to the qualitative researcher's toolbox.

\section{End Notes}

1. We were unable to judge how many forms of phenomenological analysis were performed by King et al. (2008), as although three separate individual commentaries were presented, five analysts conducted individual interpretations and six contributed to the consensual analysis.

\section{References}

References marked with an asterisk were included in the meta-study.

Ashworth, P 1996, 'Presuppose nothing! The suspension of assumptions in phenomenological psychological methodology', Journal of Phenomenological Psychology, vol. 27, no. 1, pp. $1-25$.

Bakhtin, M 1984 [1963], Problems of Dostoevsky's Poetics (C Emerson, Trans.), University of Minnesota Press, Minneapolis, MN.

Bhaskar, R 1989, Reclaiming reality: A critical introduction to contemporary philosophy, Verso, London.

Biesta, G 2010, 'Pragmatism and the philosophical foundations of mixed methods research' in A Tashakkori \& C Teddlie (eds.), Sage handbook of mixed methods in social \& behavioural research, (2nd ed.), pp. 95-118, Sage, Thousand Oaks, CA.

*Burck, C 2005, 'Comparing qualitative research methodologies for systemic research: The use of grounded theory, discourse analysis and narrative analysis', Journal of Family Therapy, vol. 27, no. 3, pp. 237-262.

Chamberlain, K 2000, 'Methodolatry and qualitative health research', Journal of Health Psychology, vol. 5, no. 3, pp. 285-296.

Chamberlain, K 2011, 'Troubling methodology', Health Psychology Review, vol. 5, no. 1, pp. 48-54. 
Chamberlain, K, Cain, T, Sheridan, J \& Dupuis, A 2011, 'Pluralisms in qualitative research: From multiple methods to integrated methods', Qualitative Research in Psychology, vol. 8, no. 2, pp. 151-169.

Coyle, A 2010, 'Qualitative research and anomalous experience: A call for interpretative pluralism', Qualitative Research in Psychology, vol. 7, no. 1, pp. 79-83.

Cresswell, JW 2007, Qualitative inquiry and research design: Choosing among five approaches, (2nd ed.), Sage, Thousand Oaks, CA.

Ellingson, LL 2009, Engaging crystallization in qualitative research: An introduction, Sage, Thousand Oaks, CA.

*Frost, N 2009, 'Do you know what I mean?': The use of a pluralistic narrative analysis approach in the interpretation of an interview', Qualitative Research, vol. 9, no. 1, pp. 9-29.

Frost, N \& Nolas, SM 2013, 'The contribution of pluralistic qualitative approaches to mixed methods evaluations', New Directions for Evaluation, Special issue: Mixed methods and credibility of evidence in evaluation, vol. 138, pp. 75-84.

Frost, N, Nolas, SM, Brooks-Gordon, B, Esin, C, Holt, A, Mehdizadeh, L \& Shinebourne, P 2010, 'Pluralism in qualitative research: The impact of different researchers and qualitative approaches on the analysis of qualitative data', Qualitative Research, vol. 10, no. 4, pp. 441-460.

*Frost, NA, Holt, A, Shinebourne, P, Esin, C, Nolas, S-M, Mehdizadeh, L \& Brooks-Gordon, B 2011, 'Collective findings, individual interpretations: An illustration of a pluralistic approach to qualitative data analysis', Qualitative Research in Psychology, vol. 8, no. 1, pp. 93-113.

Frost, NA \& Nolas, SM 2011, 'Editorial: Exploring and expanding on pluralism in qualitative research in psychology', Qualitative Research in Psychology, vol. 8, no. 2, pp. 115-119.

Garratt, D \& Hodkinson, P 1998, 'Can there be criteria for selecting research criteria? - A hermeneutical analysis of an inescapable dilemma', Qualitative Inquiry, vol. 4, no. 4, pp. 515-539. 
Guba, EG \& Lincoln, YS 1989, Fourth generation evaluation, Sage, Newbury Park, CA.

*Honan, E, Knobel, M, Baker, C \& Davies, B 2000, 'Producing possible Hannahs: Theory and the subject of research', Qualitative Inquiry, vol. 6, no. 1, pp. 9-32.

Johnson, B \& Stefurak, T 2014, 'Dialectical pluralism: A metaparadigm and process philosophy for 'dynamically combining' important differences', QMiP Bulletin, no. 17, pp. 63-69.

Johnson, M, Long, T \& White, A 2000, 'Arguments for 'British pluralism' in qualitative health research', Journal of Advanced Nursing, vol. 33, no. 2, pp. 243-249.

Kincheloe, JL 2001, 'Describing the bricolage: Conceptualizing a new rigor in qualitative research', Qualitative Inquiry, vol. 7, no. 6, pp. 679-692.

Kincheloe, JL 2005, 'On to the next level: Continuing the conceptualization of the bricolage', Qualitative Inquiry, vol. 11, no. 3, pp. 323-350.

Kincheloe, JL \& Berry, KS 2004, Rigour and complexity in educational research: Conceptualizing the bricolage, Open University Press/McGraw-Hill Education, Maidenhead.

*King, N, Finlay, L, Ashworth, P, Smith, JA, Langdridge, D \& Butt, T 2008, '“Can't really trust that, so what can I trust?": A polyvocal, qualitative analysis of the psychology of mistrust', Qualitative Research in Psychology, vol. 5, no. 2, pp. 80-102.

Lincoln, YS, Lynham, SA \& Guba, EG 2011, 'Paradigmatic controversies, contradictions, and emerging confluences, revisited', in NK Denzin \& YS Lincoln (eds.), The Sage handbook of qualitative research, (4th ed.), pp. 97-128, Sage, London.

*Lyons, AC \& Cromby, J 2010, 'Social psychology and the empirical body: Rethinking the relationship', Social and Personality Psychology Compass, vol. 4, no. 1, pp. 1-13.

Paterson, BL, Thorne, SE, Canam, C \& Jillings, C 2001, Meta-study of qualitative health research: A practical guide to meta-analysis and meta-synthesis, Sage, London.

*Robinson, OC \& Smith, JA 2010, 'Investigating the form and dynamics of crisis episodes in early adulthood: The application of a composite qualitative method', Qualitative Research in Psychology, vol. 7, no. 2, pp. 170-191. 
Sacks, H, Schegloff, EA \& Jefferson, G 1974, 'A simplest systematics for the organization of turn-taking for conversation', Language, vol. 50, no. 4, pp. 696-735.

*Savage, J 2000, 'One voice, different tunes: Issues raised by dual analysis of a segment of qualitative data', Journal of Advanced Nursing, vol. 31, no. 6, pp. 1493-1500.

Seale, C 1999, 'Quality in qualitative research', Qualitative Inquiry, vol. 5, no. 4, pp. 465-478.

*Simons, L, Lathlean, J \& Squire, C 2008, 'Shifting the focus: Sequential methods of analysis with qualitative data', Qualitative Health Research, vol. 18, no, 1, pp. 120-132.

Smith, JK \& Deemer, D 2000, 'The problem of criteria in the age of relativism', in NK Denzin \& YS Lincoln (eds.), Handbook of qualitative research, (2nd ed.), pp. 877-896, Sage, London.

Tracy, SJ 2010, 'Qualitative quality: Eight “big-tent" criteria for excellent qualitative research', Qualitative Inquiry, vol. 16, no. 10, pp. 837-851.

Walsh, R \& Koelsch, LE 2012, 'Building across fault lines in qualitative research', The Humanistic Psychologist, vol. 40, no. 4, pp. 380-390.

*Wickens, CM 2011, 'The investigation of power in written texts through the use of multiple textual analytic frames', International Journal of Qualitative Studies in Education, vol. 24, no. 2, pp. 151-164.

Willig, C 2013, Introducing qualitative research in psychology, (3rd ed.), Open University Press/McGraw-Hill Education, Maidenhead.

Yardley, L 2000, 'Dilemmas in qualitative health research', Psychology \& Health, vol. 15, no. 2, pp. 215-228. 